\title{
Axial Ratio and Gain Enhancement of a Circular-Ring Slot Antenna Using a Pair of Asymmetrical Rectangular Slots and a Parasitic Patch for a Radio Beacon on a Nanosatellite
}

\author{
Peberlin Parulian Sitompul ${ }^{1,2, *}$, Josaphat Tetuko Sri Sumantyo ${ }^{1}$, Farohaji Kurniawan ${ }^{3}$ (i) and \\ Mohammad Nasucha ${ }^{1,4}$ \\ 1 Center for Environment Remote Sensing, Chiba University, Chiba 263-8522, Japan; \\ jtetukoss@faculty.chiba-u.jp (J.T.S.S.); mohammad.nasucha@chiba-u.jp (M.N.) \\ 2 Space Science Center, Indonesian National Institute of Aeronautics and Space, Bandung 40173, Indonesia \\ 3 Aeronautic Technology Center, National Institute of Aeronautics and Space, Bogor 16350, Indonesia; \\ farohaji.kurniawan@lapan.go.id \\ 4 Department of Informatics, Universitas Pembangunan Jaya, Tangerang Selatan 15413, Indonesia; \\ mohammad.nasucha@upj.ac.id \\ * Correspondence: peberlin.sitompul@lapan.go.id or peberlin_sitompul@chiba-u.jp
}

Received: 17 January 2019; Accepted: 12 March 2019; Published: 28 March 2019

\begin{abstract}
Radio beacons enable measurements of ionospheric radio scintillations and total electron content (TEC). These beacons transmit unmodulated, phase-coherent waves in S-band frequencies. Many satellite applications require circularly polarized (CP) wideband antennas. Their compact size, lightweight, and simple fabrication method make $\mathrm{CP}$ antennas suitable for small satellite systems. The slot antenna has wideband impedance, but the $3 \mathrm{~dB}$ axial ratio bandwidth (ARBW) is narrower compared to the impedance bandwidth (IBW). In this paper, a circularly polarized circular-slotted antenna (CSA) is proposed to enhance the ARBW and the antenna gain. A pair of asymmetrical rectangular slots, a simple $50 \Omega$ feedline and a parasitic patch were introduced to a CSA to enhance the $3 \mathrm{~dB}$ ARBW and the antenna gain. Rectangular slots were inserted on the diagonal axis of the CSA, the feedline was shifted to the left side of the $x$-axis, and a parasitic patch was attached to the circular slot. The lengths of the rectangular slots correspond to the resonant frequency, and the parasitic patch width corresponds to the higher frequency of the $3 \mathrm{~dB}$ ARBW. The asymmetrical rectangular slots, the shifted feedline, and the parasitic patch successfully improved the measured $3 \mathrm{~dB} A R B W$ of the antenna by $787.5 \mathrm{MHz}$ or $35.79 \%$. The measured gain of a CSA with left-hand circular polarization (LHCP) was also improved by shifting the feedline and the rectangular slot, achieving a peak gain of 5 dBic.
\end{abstract}

Keywords: nanosatellite; microstrip antenna; slot antenna; axial ratio enhancement; circular polarization

\section{Introduction}

The Josaphat Microwave Remote Sensing Laboratory (JMRSL), Center for Environmental Remote Sensing (CEReS), Chiba University in Chiba, Japan has been conducting research and development related to ionosphere sensors onboard microsatellites since 2015 [1,2]. Developments in space technology have motivated scientists and engineers to consider the idea of a small satellite. The evolution and ongoing miniaturization of technology have led to the emergence of new small satellites, such as nanosatellites capable of performing simple and complex missions in outer space [3]. 
As a radio wave transmitter and receiver, an antenna is a critical part of a satellite system. Many satellite applications in L-band and S-band, such as Global Navigation Satellite Systems (GNSS) and satellite communication systems, require wideband circularly polarized (CP) antennas. The $C P$ antenna is resilient to multi-path interferences, the Faraday rotation effect, and polarization mismatch, especially for small satellites without attitude and stabilization control.

The proposed satellite antenna for ionospheric monitoring [4] has a quadrifilar helical antenna [5] with a crossed-dipole, but these antennas are an inappropriate size for nanosatellites. The compact size, lightweight, and simple fabrication method make this antenna suitable for a satellite system. CP printed-slot antennas have been broadly developed to achieve wide $3 \mathrm{~dB}$ axial ratio bandwidth (ARBW) fed by a coplanar wave (CPW) and microstrip line. A CPW-fed slot antenna with a lightening feed line and inverted-L grounded strips [6] produced a $3 \mathrm{~dB}$ ARBW of $48.8 \%$ and $4.2 \mathrm{dBic}$ peak gain, whereas a CPW-fed symmetric-aperture antenna [7] produced a broader $3 \mathrm{~dB}$ ARBW of $68 \%$ and $4 \mathrm{dBic}$ peak gain. Microstrip-line-fed ring slot antennas have lower bandwidth and gain, such as the square-ring slot antenna [8]. Better gains have been achieved by microstrip-line-fed wide-slot antennas, such as the patch-loaded square slot antenna [9] that produces a $3 \mathrm{~dB} A R B W$ of $12 \%$ with a peak gain of $5.5 \mathrm{dBic}$, and the L-shaped microstrip-fed circular-shaped slot antenna [10] that achieves a $3 \mathrm{~dB}$ ARBW of $44 \%$ with a peak gain of 5 dBic. Gain enhancement with substrate-integrated waveguide (SIW) cavity-backed antenna using $T E_{410}$ [11] produced a gain of $9.2 \mathrm{dBic}$ with no $3 \mathrm{~dB} A R B W$. Antennas with asymmetrical square-ring slots and a shifted feedline on the $x$-axis [12] presented a $3 \mathrm{~dB}$ ARBW of $4.3 \%$ and a gain of $4.3 \mathrm{dBic}$. Wider ring slots incorporated with grounded hat-shaped patches and a curved feed line [13] significantly enhanced the ARBW with a $3 \mathrm{~dB}$ ARBW of $65 \%$ and a peak gain of 5.1 dBic. However, the drawbacks are a weaker structure and a much larger size.

The conventional circular-slotted antenna is linearly polarized. Therefore, changing the structure, such as introducing perturbation to the slot, a hybrid coupler [14,15], and two linked slot rings [16], has been proposed to transform the polarization from linear mode to circular mode. However, these modifications yield narrower $3 \mathrm{~dB}$ ARBW than impedance bandwidth (IBW). As such, improving the $3 \mathrm{~dB}$ ARBW technique is necessary. Many methods have been investigated for this purpose, including a slanted rectangular slot with a circular patch [17] and a narrow horizontal slot on the equilateral triangular patch antenna [18]. However, these modifications did not improve the impedance bandwidth, axial ratio bandwidth, or gain.

The goal of this study was to create a design for enhancing the CP performance of a circular-slotted antenna (CSA) to achieve a wide $3 \mathrm{~dB}$ ARBW close to its IBW, and a higher gain. CP radiation was generated by creating two truncations, a simple $50 \Omega$ microstrip feedline, and a parasitic patch. The truncations were created by a pair of asymmetrical rectangular slots on the diagonal axis of the grounded patch to generate AR polarization. The feedline was shifted to the left side on the $x$-axis to enhance antenna gain and deformed by introducing a stub on the upper edge of the feedline to match the antenna impedance. To improve the $3 \mathrm{~dB}$ ARBW of the CSA antenna, a rectangular parasitic patch was loaded into the circular slot, which generated a higher frequency.

\section{Circular-Slotted Antenna}

The design included a conventional model and model 1, as depicted in Figure 1. The conventional CSA (Figure 1a) applies linear polarization (LP) radiation. The slot radius $R$ determines the resonant frequency of this antenna. The antenna is simulated on a substrate with a relative permittivity $\varepsilon_{r}$ of 2.17, thickness $h$ of $1.6 \mathrm{~mm}$, loss tangent of 0.0005 , and slot radius $R$ of $26.5 \mathrm{~mm}$. The copper thickness $t$ of $0.035 \mathrm{~mm}$, the antenna width $W$ of $95 \mathrm{~mm}$, and the length $L$ of $100 \mathrm{~mm}$ yield a resonant frequency of $2.17 \mathrm{GHz}$. The feedline length $L_{f 1}$ is $40 \mathrm{~mm}, L_{f 2}$ is $8 \mathrm{~mm}$, width $W_{f 1}$ is $4 \mathrm{~mm}$, and $W_{f 2}$ is $4 \mathrm{~mm}$. Figure 2 depicts the final design, referred to as model 2. The dimensions of the CSA model are provided in Table 1. 


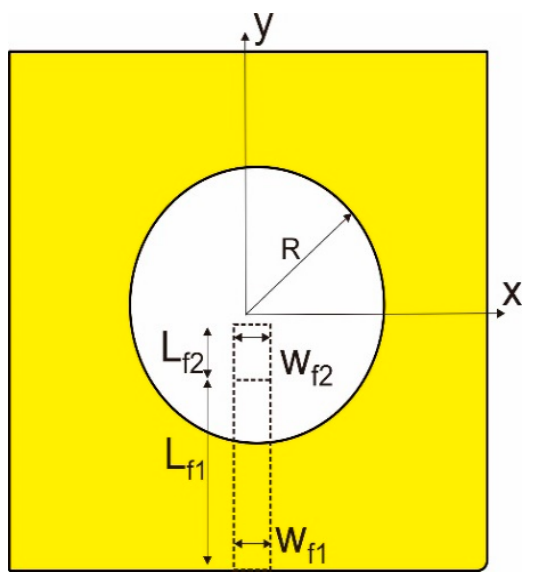

(a)

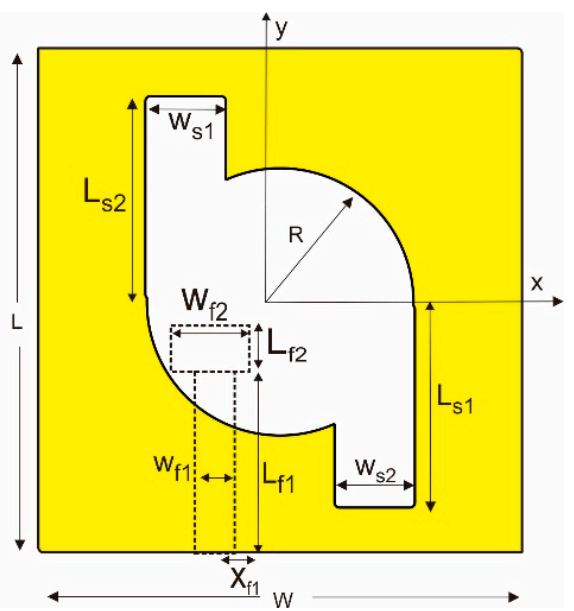

(b)

Figure 1. Geometry of a circular-slotted antenna (CSA): (a) conventional model and (b) model 1.

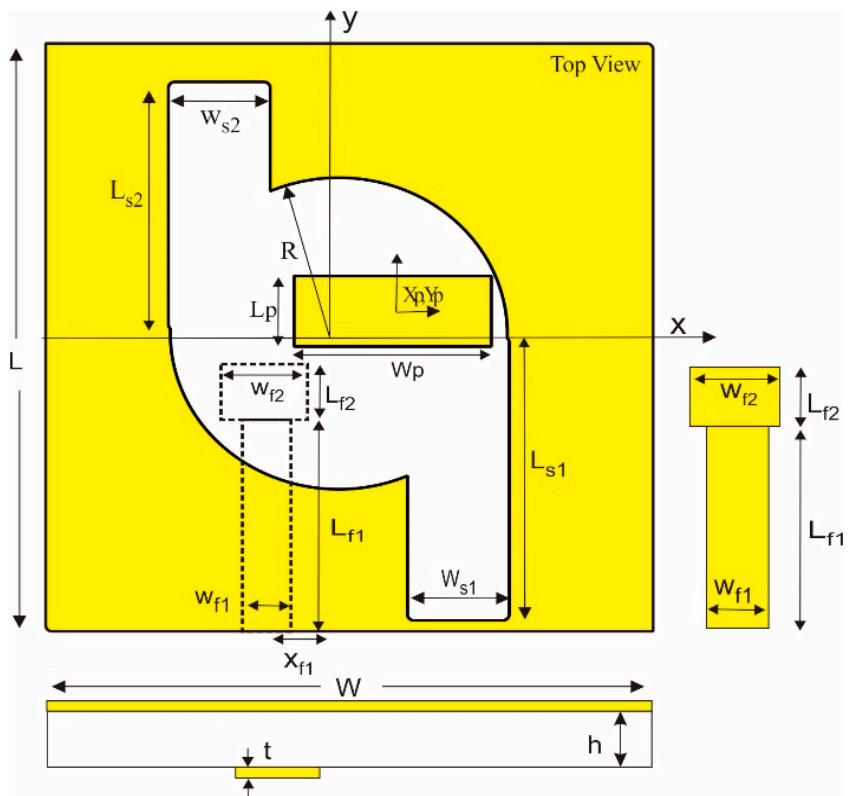

Figure 2. The geometry of model 2. The microstrip feedline is located on the right side, and the edge profile of the antenna is drawn on the bottom.

Table 1. Dimensions of CSA models.

\begin{tabular}{ccccccccccc}
\hline Models & $\begin{array}{c}R \\
(\mathbf{m m})\end{array}$ & $\begin{array}{c}\boldsymbol{L}_{s 1} \\
(\mathbf{m m})\end{array}$ & $\begin{array}{c}\boldsymbol{L}_{s 2} \\
(\mathbf{m m})\end{array}$ & $\begin{array}{c}W_{f 1} \\
(\mathbf{m m})\end{array}$ & $\begin{array}{c}W_{f 2} \\
(\mathbf{m m})\end{array}$ & $\begin{array}{c}X_{f 1} \\
(\mathbf{m m})\end{array}$ & $\begin{array}{c}\boldsymbol{L}_{p} \\
(\mathbf{m m})\end{array}$ & $\begin{array}{c}W_{p} \\
(\mathbf{m m})\end{array}$ & $\begin{array}{c}X_{p} \\
(\mathbf{m m})\end{array}$ & $\begin{array}{c}\boldsymbol{Y}_{p} \\
(\mathbf{m m})\end{array}$ \\
\hline Conventional & 26.5 & - & - & 4 & 4 & 0 & - & - & - & - \\
\hline Model 1 & 26.5 & 40.79 & 40.79 & 4 & 4 & -9 & - & - & - & - \\
\hline Model 2 & 26.5 & 48 & 40 & 4 & 10 & -9 & 12 & 31 & 8 & 5 \\
\hline
\end{tabular}

\section{A Pair of Rectangular Slots and Parasitic Patch for the $3 \mathrm{~dB}$ ARBW and the Gain Enhancement}

\subsection{A Pair of Symmetrical Rectangle Slots (Model 1)}

The CP is converted from the LP antenna (conventional model) by modifying the slot structure [16], and its feedline is positioned to the side of the wide slot [19]. In model 1, the feedline is shifted toward the left side of the $x$-axis, and two symmetrical rectangular slots are introduced on the diagonal of the grounded patch. The feedline is shifted to the left side with $X_{f 1}$ of $9 \mathrm{~mm}$. The rectangular slots have a 
length $L_{s 1}$ of $40.79 \mathrm{~mm}, W_{s 1}$ of $16 \mathrm{~mm}, L_{s 2}$ of $40.79 \mathrm{~mm}$, and $W_{s 2}$ of $16 \mathrm{~mm}$. This design was used to generate the $\mathrm{CP}$ wave and increase the antenna gain, as shown in Figure 1b. The lengths $L_{s 1}$ and $L_{s 2}$ also influence the resonant frequency by changing the slot size. The larger the value of $L_{s 1}$, the higher the resonant frequency, and the lower the axial ratio. A wider impedance bandwidth compared with the conventional model was produced.

With a slot length of $0 \mathrm{~mm}$, the center frequency $S_{11}$ shifts to a higher frequency of $2.37 \mathrm{GHz}$ with an impedance bandwidth of $1.11 \mathrm{GHz}$. The antenna gain is $1.92 \mathrm{dBic}$ at a frequency of $2.2 \mathrm{GHz}$, with a peak gain of $2.4 \mathrm{dBic}$ at a frequency of $2.6 \mathrm{GHz}$. When the slot length is $30 \mathrm{~mm}$, the frequency center shifts to a higher frequency of $2.59 \mathrm{GHz}$. This model achieves a peak gain of $4.06 \mathrm{dBic}$, but fails to generate the $3 \mathrm{~dB}$ axial ratio. When the rectangular slot length is $40.79 \mathrm{~mm}$, a $3 \mathrm{~dB}$ axial ratio is generated at the center frequency of $2.34 \mathrm{GHz}$ with an ARBW of $270 \mathrm{MHz}$. If the slot length is more than $40.79 \mathrm{~mm}$, the axial ratio is better (lower), but the center frequency $S_{11}$ shifts to a higher frequency. The influence of slot lengths $L_{s 1}$ and $L_{s 2}$ on $S_{11}$, the axial ratio, and the gain are depicted in Figure $3 \mathrm{a}-\mathrm{c}$, respectively.

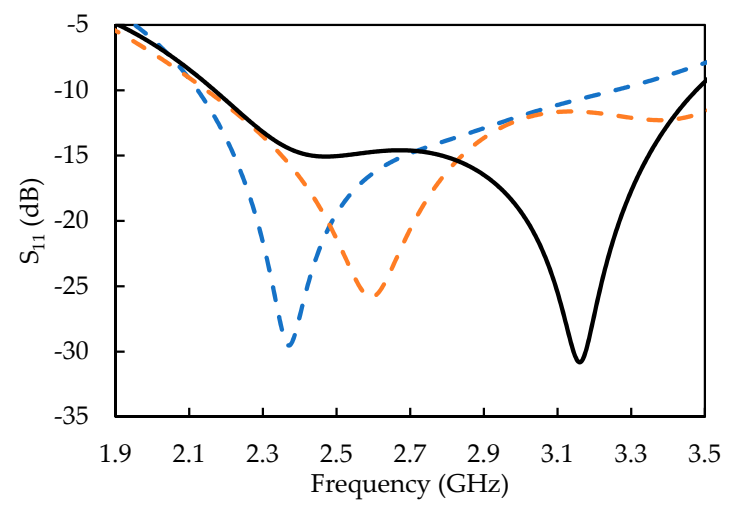

(a)

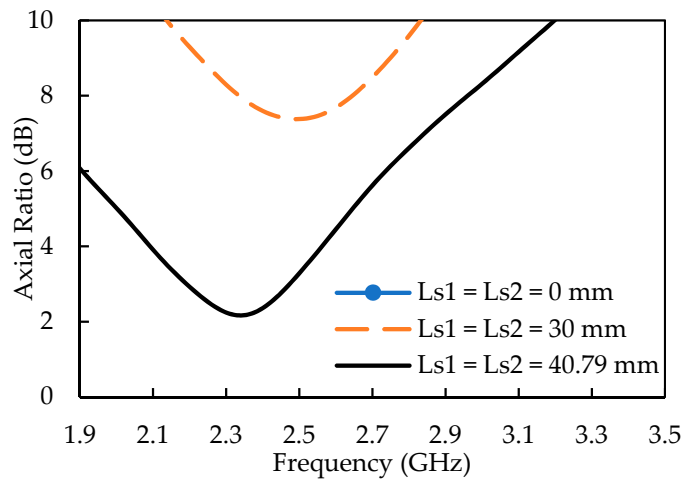

(b)

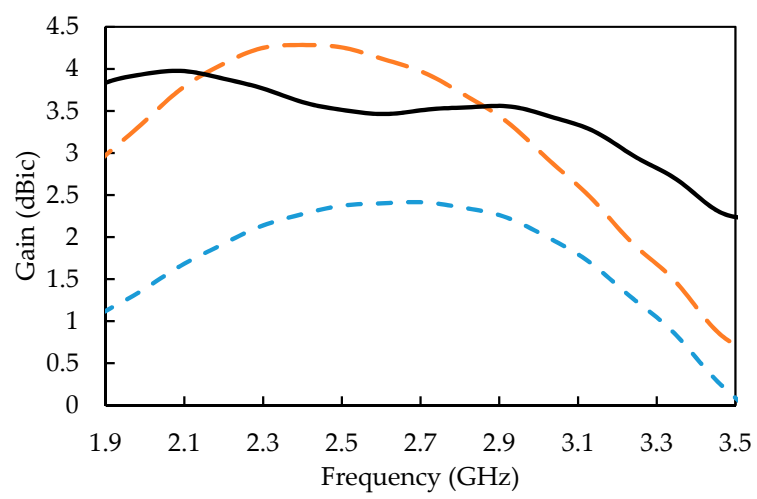

(c)

Figure 3. Effect of the symmetrical slot length of 0,30 , and $40.79 \mathrm{~mm}$ on (a) $S_{11},(\mathbf{b})$ axial ratio, and (c) gain.

\subsection{A Rectangular Parasitic Patch (Model 2)}

CP performance improvement of the CSA model 1 was necessary as its $3 \mathrm{~dB}$ ARBW was much narrower than its impedance bandwidth. Many methods have been investigated to enhance the 3 dB ARBW using a parasitic center patch [20] and a coplanar parasitic patch [21]. In this design, a parasitic patch on the circular slot was introduced to model 1 to generate another resonant frequency to broaden the $3 \mathrm{~dB}$ ARBW. The performance of the parasitic patch is influenced by a current path that depends on the parasitic length $W_{p}$, the parasitic width $L_{p}$, and its parasitic center on the $x$ - and $y$-axes. In this step, the effect of the parasitic width, patch length, and its center on the $x$-and $y$-axes are simulated. Figure $4 a-d$ depict the simulation results. Figure $4 a$ shows the effect of the parasitic 
widths $W_{p}$ of 0,20 , and $31 \mathrm{~mm}$ with a fixed parasitic length $L_{p}$ of $12 \mathrm{~mm}, X_{p}$ of $8 \mathrm{~mm}$, and $Y_{p}$ of $5 \mathrm{~mm}$ on the $3 \mathrm{~dB}$ axial ratio bandwidth. The parasitic widths of 0 and $20 \mathrm{~mm}$ produced $3 \mathrm{~dB}$ axial ratio bandwidths of 270 and $210 \mathrm{MHz}$, respectively. The antenna gain was lower, with a value of $3.47 \mathrm{dBic}$ at 2.2 GHz. The parasitic width $W_{p}$ of $31 \mathrm{~mm}$ generated a CP in the center frequencies of 2.35 and 3.44 $\mathrm{GHz}$, producing $3 \mathrm{~dB}$ axial ratios of 360 and $160 \mathrm{MHz}$. This antenna design produced an antenna gain of $3.64 \mathrm{dBic}$ at the frequency of $2.2 \mathrm{GHz}$. This simulation result shows that when the parasitic patch width is $31 \mathrm{~mm}$, a better axial ratio bandwidth is created. Figure $4 \mathrm{~b}$ shows the effect of the parasitic lengths $L_{p}$ of 2, 6, and $12 \mathrm{~mm}$ with a fixed parasitic width $W_{p}$ of $31 \mathrm{~mm}, X_{p}$ of $8 \mathrm{~mm}$, and $Y_{p}$ of $5 \mathrm{~mm}$ on the $3 \mathrm{~dB}$ axial ratio bandwidth. The parasitic length $L_{p}$ of $2 \mathrm{~mm}$ generated dual $\mathrm{CP}$ frequencies of $2.35 \mathrm{GHz}$ and $2.58 \mathrm{GHz}$, with $3 \mathrm{~dB}$ ARBWs of $229 \mathrm{MHz}$ and $180 \mathrm{MHz}$, respectively.

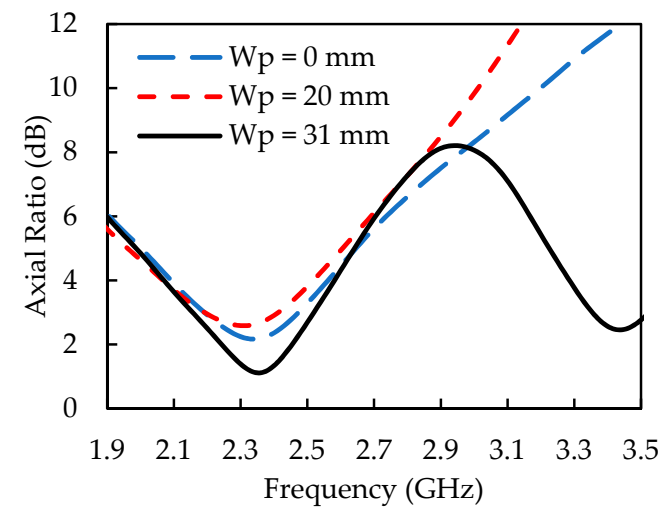

(a)

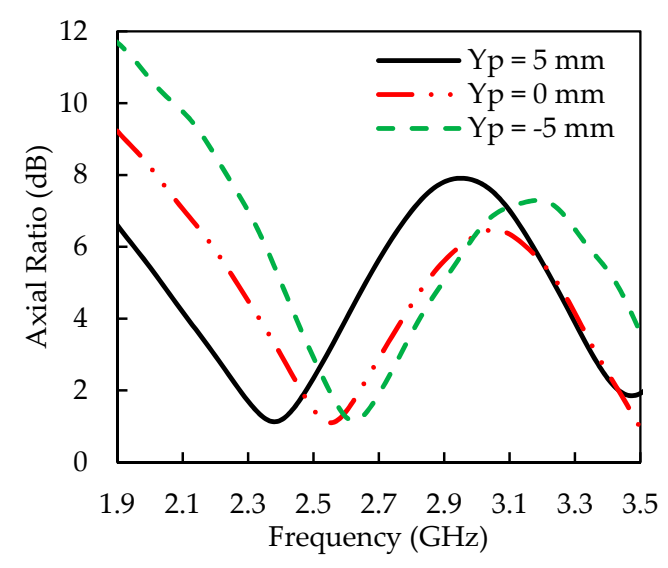

(c)

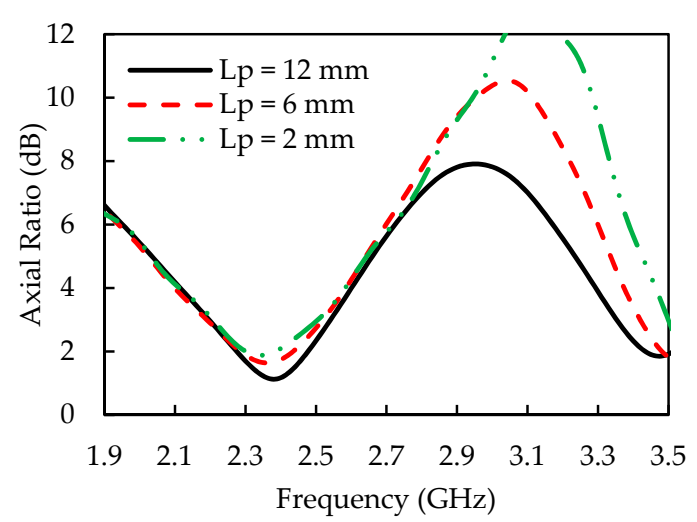

(b)

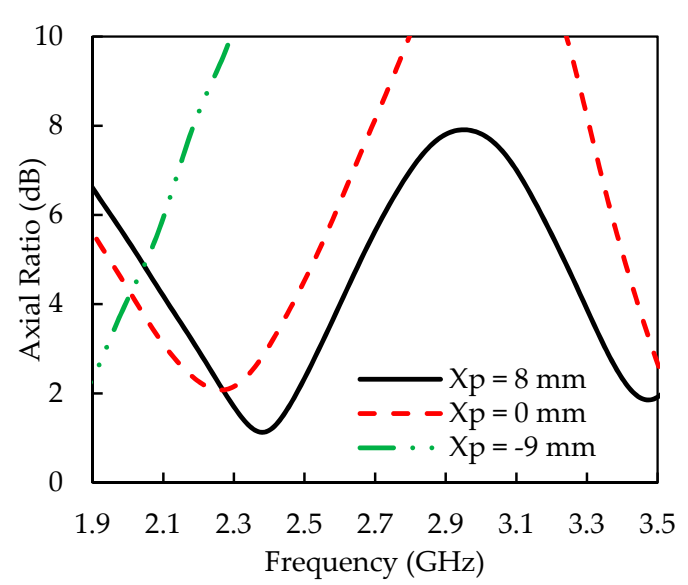

(d)

Figure 4. Variation in the axial ratio in relation to: (a) parasitic length $L_{p}$, (b) parasitic width $W_{p}$, (c) parasitic center on the $y$-axis $Y_{p}$, and (d) parasitic center on the $x$-axis $X_{p}$.

When the patch length $L_{p}$ was $6 \mathrm{~mm}$, the $3 \mathrm{~dB}$ axial ratios were 300 and $220 \mathrm{MHz}$ at frequencies of 2.37 and $3.55 \mathrm{GHz}$, respectively. When the patch length $L_{p}$ was $12 \mathrm{~mm}$, the $3 \mathrm{~dB}$ axial ratios were 310 and $250 \mathrm{MHz}$ in the center frequencies of 2.38 and $3.49 \mathrm{GHz}$, respectively. The center frequency of the $\mathrm{CP}$ shifted closer to each other and the gain increased by $4.1 \mathrm{dBic}$.

Figure $4 \mathrm{c}$ shows the effect of the parasitic center $Y_{p}$ of $-5,0$, and $5 \mathrm{~mm}$ with a fixed parasitic width $W_{p}$ of $31 \mathrm{~mm}$, and $L_{p}$ of $12 \mathrm{~mm}$ on the $3 \mathrm{~dB}$ axial ratio bandwidth. When the parasitic center $Y_{p}$ was $-5 \mathrm{~mm}$, the $3 \mathrm{~dB}$ center frequencies $(\mathrm{CF})$ were 2.63 and $3.7 \mathrm{GHz}$. When the parasitic center $Y_{p}$ was $0 \mathrm{~mm}$, the $3 \mathrm{~dB} C F$ were 2.56 and $3.56 \mathrm{GHz}$. When $Y_{p}$ was $5 \mathrm{~mm}$, the $3 \mathrm{~dB} C F$ occurred at 2.39 and $3.45 \mathrm{GHz}$. The simulation result showed that the parasitic center $Y_{p}$ controls the $3 \mathrm{~dB} C F$. Figure $4 \mathrm{~d}$ shows the effect of the parasitic center $X_{p}$ of $-9,0$, and $8 \mathrm{~mm}$ with the fixed parasitic width $W_{p}$ of 31 $\mathrm{mm}$ and $L_{p}$ of $12 \mathrm{~mm}$ on the $3 \mathrm{~dB}$ axial ratio bandwidth. When the parasitic center $X_{p}$ was $-9,0$, and 8 
$\mathrm{mm}$, the $3 \mathrm{~dB}$ center frequency generated $3 \mathrm{~dB}$ ARBWs of $190 \mathrm{MHz}, 290$ and $190 \mathrm{MHz}$, and 340 and $250 \mathrm{MHz}$, respectively. The simulation result showed that the parasitic center $X_{p}$ generates a higher frequency when its position is on the positive $x$-axis.

However, a combination of the symmetrical slot length and a rectangular parasitic patch failed to enhance the $3 \mathrm{~dB}$ ARBW. The next step was to extend the slot lengths $L_{s 1}$ to $48.79 \mathrm{~mm}$ and $L_{\mathrm{s} 2}$ to $40.79 \mathrm{~mm}$. This modification successfully enhanced the $3 \mathrm{~dB}$ axial ratio up to $51.52 \%$ in the frequency range of 2.12-3.35 GHz. This design also increased the antenna gain up to $4.71 \mathrm{dBic}$ at the frequency of $2.2 \mathrm{GHz}$, with a peak gain of $4.8 \mathrm{dBic}$ at the frequency of $2.28 \mathrm{GHz}$. However, the impedance frequency shifted to a higher frequency of $2.27-3.32 \mathrm{GHz}$, with the deepest curve of $-45 \mathrm{~dB}$ at the center frequency of $2.69 \mathrm{GHz}$. This impedance frequency must have been shifted to a lower frequency; therefore, to overcome this problem, the feedline width was deformed with a $W_{f 2}$ of $10 \mathrm{~mm}$, as depicted in Figure 2. Model 2 has an impedance bandwidth of $1.84-2.72 \mathrm{GHz}$, an antenna gain of up to $4.65 \mathrm{dBic}$, an ARBW of $2.21-3.26 \mathrm{GHz}$ or $51.52 \%$, and a deep curve of $0.28 \mathrm{~dB}$ at the frequency of $2.42 \mathrm{GHz}$. Therefore, proper tuning is critical to determine the best parameters that produce a wider impedance bandwidth, a wider ARBW, and a higher gain. The comparison of the simulation results of the conventional model, model 1, and model 2 is depicted in Figure 5, and the performance is compared in Table 2 .

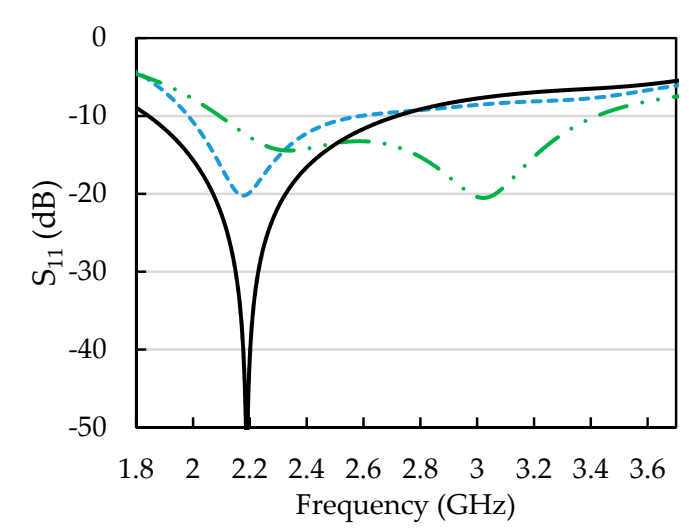

(a)

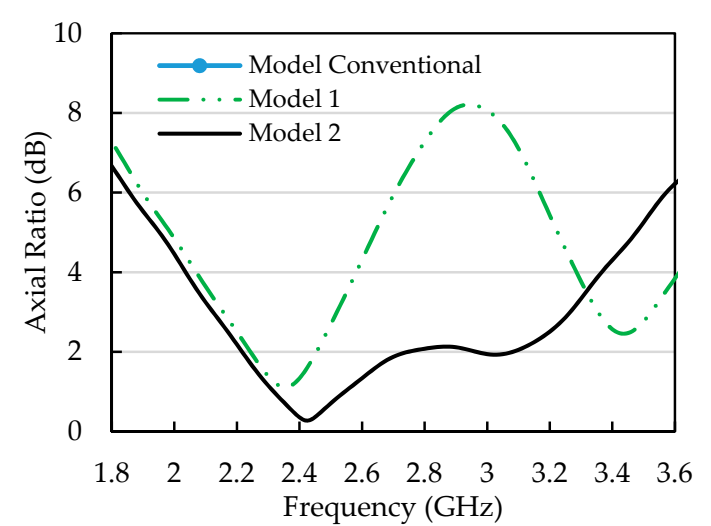

(b)

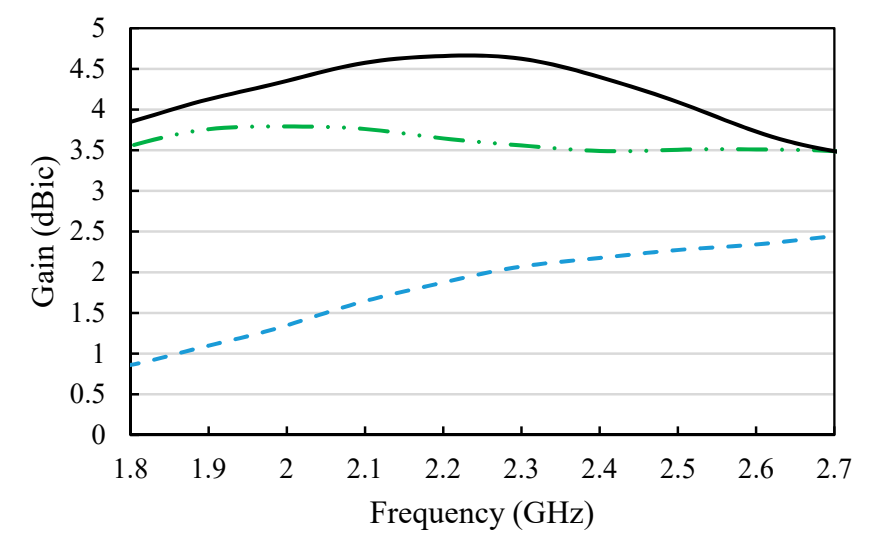

(c)

Figure 5. Comparison of the conventional model, model 1, and model 2: (a) $S_{11}$, (b) axial ratio, and (c) antenna gains.

Figure $6 \mathrm{a}, \mathrm{b}$ show the measured and the simulated axial ratios as a function of theta $(\theta)$ at the frequencies of $2.2 \mathrm{GHz}$ and $2.4 \mathrm{GHz}$. At $2.2 \mathrm{GHz}$, the measured and simulated AR in the E-plane and $\mathrm{H}$-plane produced a good result, even though the measured result was a little higher than the simulated result in the E-plane. At 2.4 GHz in the E-plane and H-plane, the measured and simulated results were also good, even though the line pattern was not entirely similar. 
Table 2. Performance of the CSA conventional model, model 1, and model 2.

\begin{tabular}{cccccc}
\hline Model & $\begin{array}{c}f_{c} \text { ibw } \\
(\mathbf{G H z})\end{array}$ & $\begin{array}{c}\text { Impedance Bandwidth } \\
\text { IBW (GHz), \% }\end{array}$ & $\begin{array}{c}f_{c} \text { arbw } \\
\text { (GHz) }\end{array}$ & $\begin{array}{c}\text { 3 dB ARBW } \\
\text { (GHz), \% }\end{array}$ & $\begin{array}{c}\text { Gain } \\
\text { (dBic) }\end{array}$ \\
\hline Conventional & 2.17 & $1.98-2.58(27.26 \%)$ & - & - & 1.85 \\
Model 1 & 3.02 & $2.10-3.41(43.43 \%)$ & 2.36 & $2.16-2.52(15.25 \%)$ & 3.65 \\
Model 2 & 2.18 & $1.84-2.71(39.62 \%)$ & 2.42 & $2.13-3.26(46.69 \%)$ & 4.66 \\
\hline
\end{tabular}

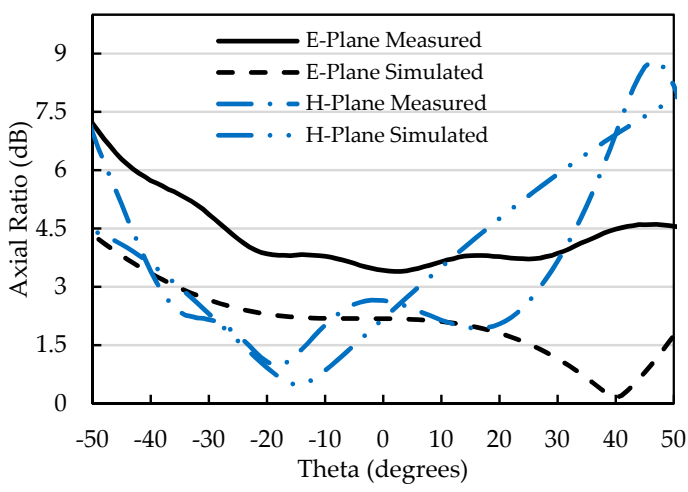

(a)

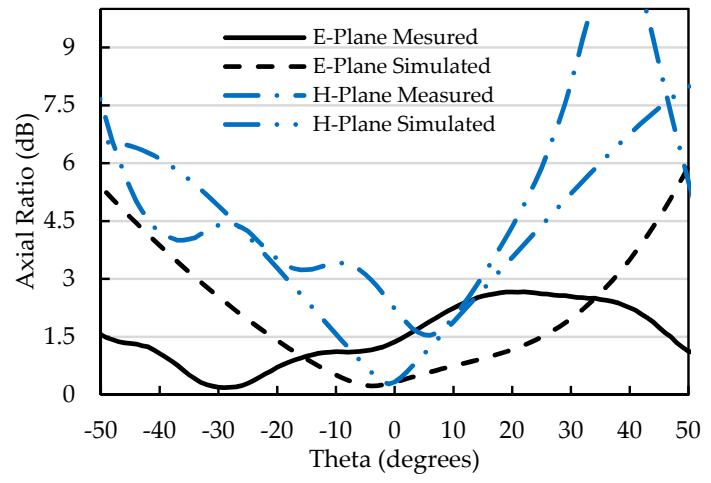

(b)

Figure 6. The measured and the simulated axial ratio (AR) vs. theta $(\theta)$ at frequencies of (a) $2.2 \mathrm{GHz}$ and (b) $2.4 \mathrm{GHz}$.

Figure 7 shows the electric field distribution at a frequency of $2.2 \mathrm{GHz}$ at $0,45,90,135$, and $180^{\circ}$. The electric field was dominant on the end of the upper feedline. For the electric field phase of 0 and $180^{\circ}$, the amplitude was dominant on the diagonal of the patch and the top right corner. When the electric field phase was $45^{\circ}$, the amplitude was dominant in the middle of the patch aligned with feedline and on the bottom left corner. The electric fields showed the left-hand pattern.

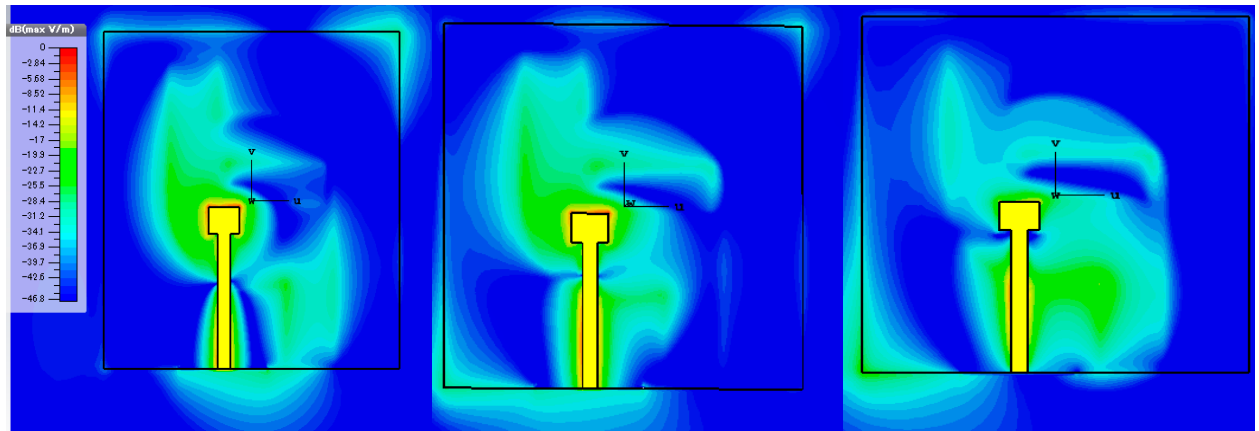

(a) (c)

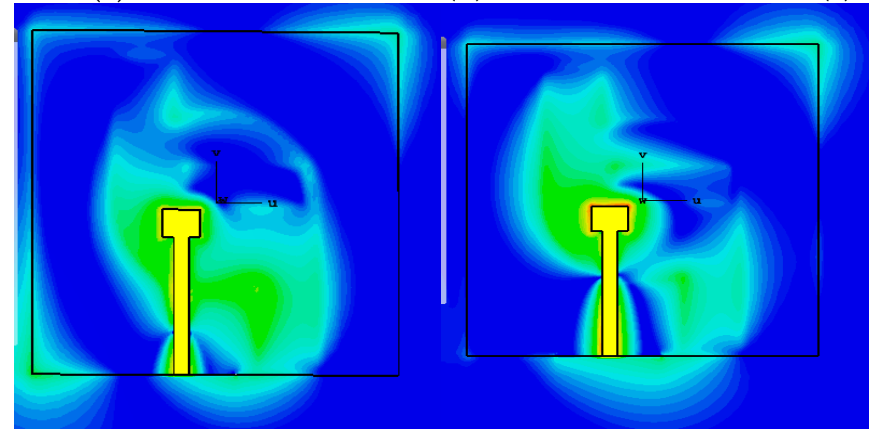

(d)

(e)

Figure 7. Electric field distribution at a frequency of $2.2 \mathrm{GHz}$ at: (a) 0 , (b) 45, (c) 90, (d) 135, and (e) 180 degrees. 


\section{Results and Discussion}

Model 2 had to be verified to confirm the simulation results. For this purpose, model 2 was manufactured as shown in Figure 8 and was measured using an RF Vector Network Analyzer (E5062A, ENA-L, Agilent) in an anechoic chamber. Figure 9a highlights that the impedance bandwidth of the fabricated antenna was in good agreement with the simulation model. The simulated results produced an impedance bandwidth of $862.5 \mathrm{MHz}$ from 1.85 to $2.71 \mathrm{GHz}$, whereas the measured result recorded an impedance bandwidth of $1.04 \mathrm{GHz}$ from 1.77 to $2.81 \mathrm{GHz}$.

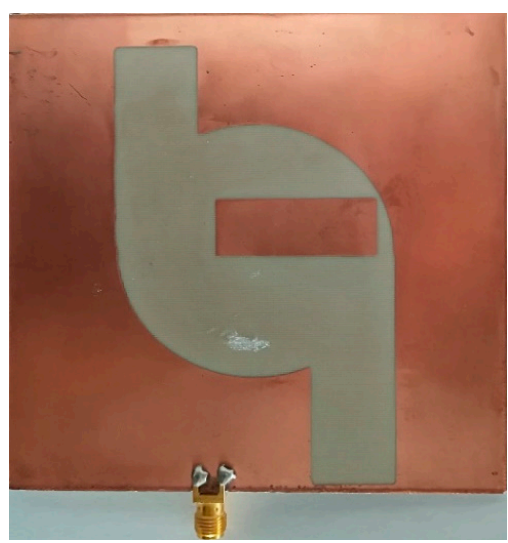

(a)

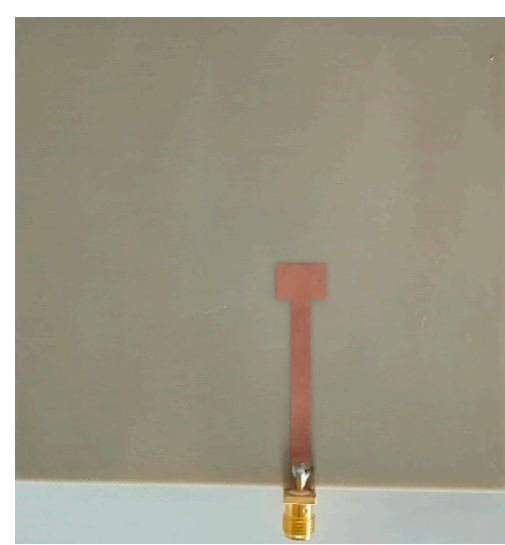

(b)

Figure 8. Fabricated antenna: (a) the antenna ground on the front side and (b) the feedline on the back side.

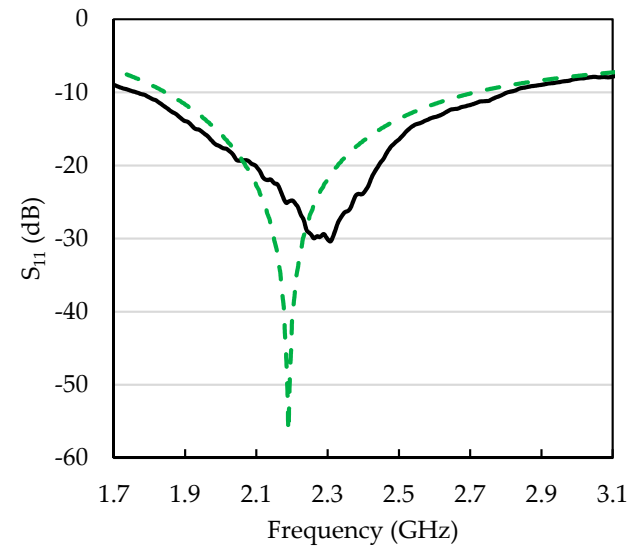

(a)

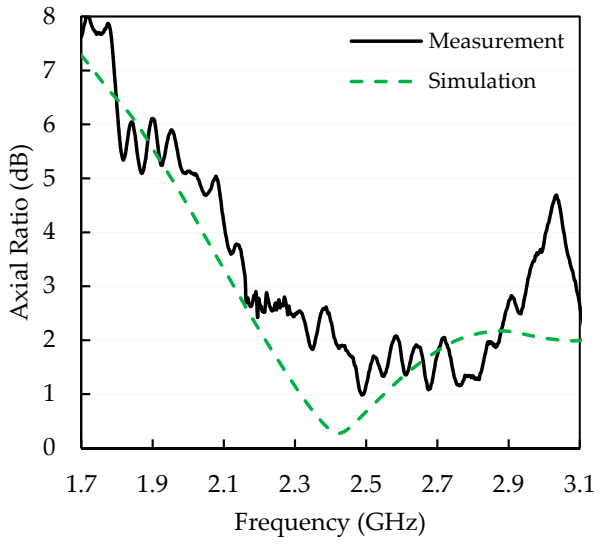

(b)

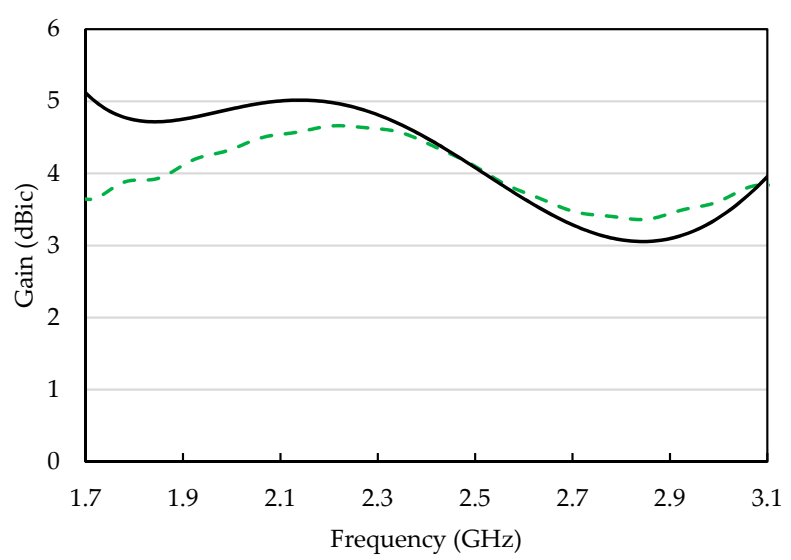

(c)

Figure 9. Simulated and measured (a) $S_{11},(\mathbf{b})$ axial ratio, and (c) antenna gain. 
The CP performance of the manufactured antenna conformed to the simulated model as illustrated in Figure 9b. The fabricated antenna produced a $3 \mathrm{~dB}$ ARBW of $787.5 \mathrm{MHz}$ from $2.1625-2.95 \mathrm{GHz}$, which was narrower than the simulated $1.13 \mathrm{GHz}$ range of 2.13-3.26 GHz. The measured ARBW was located entirely in the measured impedance bandwidth coverage. Figure $9 \mathrm{c}$ shows the antenna gain. The measured average gain generated a peak gain of $5 \mathrm{dBic}$ at the lower frequency of $2.2 \mathrm{GHz}$ and a lower gain of $3 \mathrm{dBic}$ at the higher frequency of $2.8 \mathrm{GHz}$.

The radiation patterns of the fabricated antenna were also measured in an anechoic chamber to confirm the simulation result. Figure 10 shows the measured and simulated far-field radiation patterns of the CSA when it is radiated by left-hand circular polarization (LHCP) and right-hand circular polarization (RHCP) waves sequentially. The antenna produced bidirectional radiation with both LHCP and RHCP operations radiated toward the $+z$ direction $\left(\theta=0^{\circ}\right)$ and $-z$ direction $\left(\theta=180^{\circ}\right)$, respectively. The measured E-plane far-field radiation patterns for $1.8 \mathrm{GHz}, 2 \mathrm{GHz}, 2.2 \mathrm{GHz}, 2.4 \mathrm{GHz}$, and $2.6 \mathrm{GHz}$ in Figure 10a-e, respectively, showed good agreement with the simulated results at the corresponding frequencies.

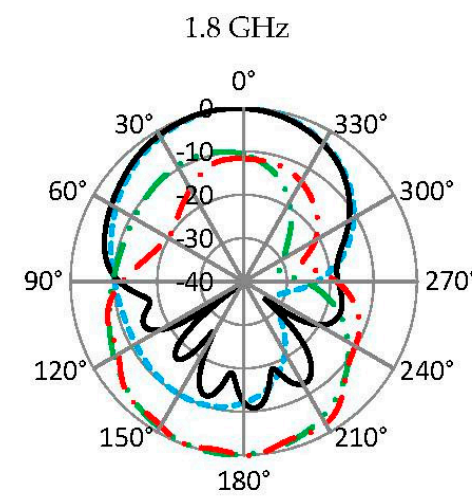

(a)

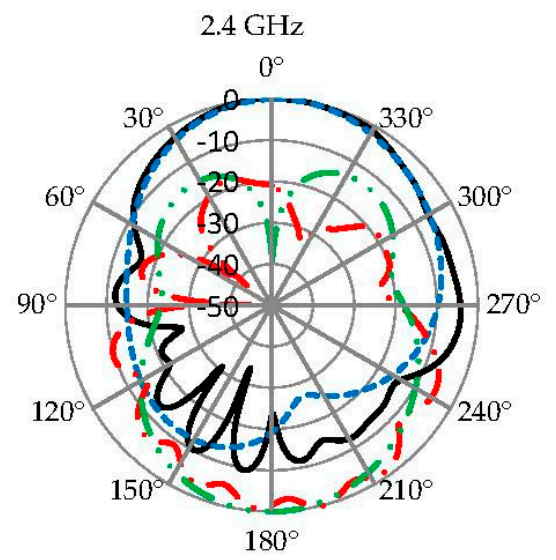

(d)

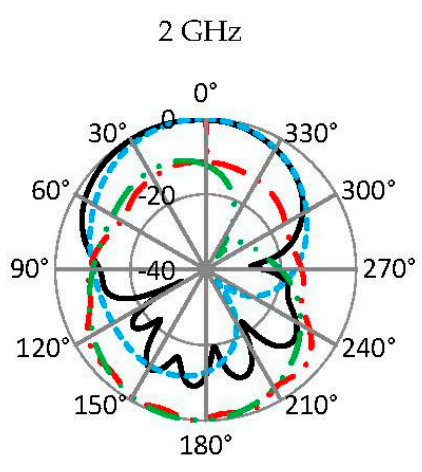

(b)

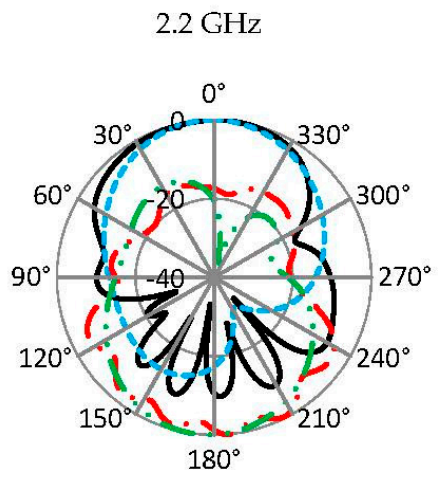

(c)

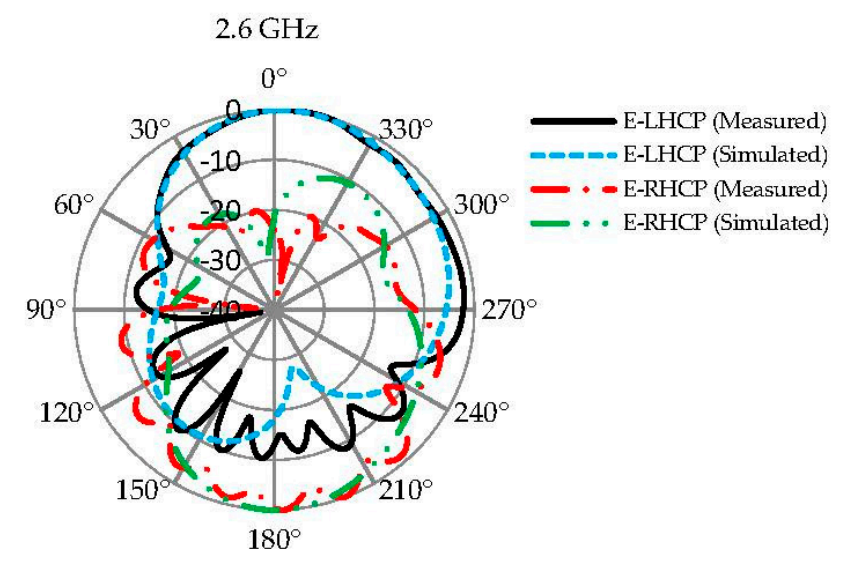

(e)

Figure 10. Measured and simulated E-plane radiation patterns of the antenna at (a) $1.8 \mathrm{GHz},(\mathbf{b}) 2 \mathrm{GHz}$, (c) $2.2 \mathrm{GHz}$, (d) $2.4 \mathrm{GHz}$, and (e) $2.6 \mathrm{GHz}$.

The performance and dimensions of the measured antenna are compared with those of some related wideband CP printed-slot antennas reported in the literature in Table 3. The proposed CSA with two asymmetrical rectangular slots and a parasitic patch had a higher peak gain compared to those reported in previous studies [6-8] and a broader $3 \mathrm{~dB}$ ARBW compared to those reported by Row et al. [8] and Tseng et al. [10]. 
Table 3. Comparison of circularly polarized (CP) printed-slot antenna performance.

\begin{tabular}{cccccc}
\hline Reference & $f_{\boldsymbol{c}} \mathbf{( M H z )}$ & $\begin{array}{c}\text { 3 dB Axial Ratio } \\
\text { Bandwidth (ARBW) (\%) }\end{array}$ & $\begin{array}{c}\text { Impedance } \\
\text { Bandwidth (IBW) (\%) }\end{array}$ & $\begin{array}{c}\text { Peak Gain } \\
\text { (dBic) }\end{array}$ & $\begin{array}{c}\text { Dimension } \\
(\mathbf{m m})\end{array}$ \\
\hline$[6]$ & 2745 & 48 & 51 & 4.2 & $60 \times 60 \times 0.8$ \\
{$[7]$} & 3625 & 68 & 107 & 4 & $60 \times 60 \times 1.6$ \\
{$[8]$} & 1590 & 6.3 & 14.7 & 3.6 & $54 \times 54 \times 1.6$ \\
{$[10]$} & 2375 & 12 & 39 & 5.5 & $120 \times 120 \times 33$ \\
Proposed & 2200 & 35.79 & 47.27 & 5 & $95 \times 100 \times 1.6$ \\
\hline
\end{tabular}

\section{Conclusions}

In this study, a conventional CSA was converted from linear polarization to circular polarization by introducing a shifted feedline and two equal rectangular slots to the circular-slotted patch. This design yielded a $3 \mathrm{~dB}$ ARBW narrower than its impedance bandwidth. The proposed method to enhance the $3 \mathrm{~dB} A R B W$ involved inserting two asymmetrical rectangular slots and a parasitic patch. Both asymmetrical rectangular slots and the parasitic patch successfully improved the measured 3 dB ARBW of $787.5 \mathrm{MHz}$ by $35.79 \%$ from 2.16 to $2.95 \mathrm{GHz}$. We confirmed that the two asymmetrical rectangular slots and the parasitic patch improved the gain. The measured average gain generated a peak gain of up to $5 \mathrm{dBic}$ at the frequency of $2.2 \mathrm{GHz}$. The proposed antenna achieved a measured impedance bandwidth of $1.04 \mathrm{GHz}$, or equal to $47.27 \%$, from 1.77 to $2.81 \mathrm{GHz}$. Thus, this design can be implemented for applications that require a wideband circularly polarized antenna.

Author Contributions: Conceptualization, P.P.S. and J.T.S.S.; methodology, P.P.S. and F.K.; software, P.P.S. and F.K.; validation, P.P.S. and F.K.; formal analysis, P.P.S.; investigation, P.P.S.; writing and the original draft preparation, P.P.S.; writing, review, and editing, P.P.S., F.K., J.T.S.S. and M.N.; supervision, J.T.S.S.; project administration, J.T.S.S.; funding acquisition, J.T.S.S.

Funding: This research is partially supported by the Chiba University Strategic Priority Research Promotion Program FY2016-FY2018.

Acknowledgments: This work was supported by the Indonesian National Institute of Aeronautics and Space (LAPAN); Ministry of Research, Technology, and Higher Education (RISET-PRO).

Conflicts of Interest: The authors declare no conflict of interest.

\section{References}

1. Sri Sumantyo, J.T.; Imura, N. Development of GNSS-RO and EDTP sensors onboard microsatellite for Ionosphere monitoring. In Proceedings of the 2015 IEEE International Geoscience and Remote Sensing Symposium (IGARSS), Milan, Italy, 26-31 July 2015.

2. Sri Sumantyo, J.T. Development of Microsatellites for Atmospheric and Land Deformation Observation. In Proceedings of the Asia Oceania Geoscience Symposium (AOGS), Hokkaido, Japan, 28 July-1 August 2014; p. 219.

3. Nugent, R.; Munakata, R.; Chin, A.; Coelho, R.; Puig-Suari, J. The cubesat: The picosatellite standard for research and education. Aerosp. Eng. 2008, 805, 756-5087.

4. Pansomboon, R.; Phongcharoenpanich, C.; Phudpong, R. Design of a Dual-Band Quadrifilar Helical Antenna for Radio Beacon Receiver. In Proceedings of the 2011 International Symposium on Intelligent Signal Processing and Communications Systems (ISPACS), Chiang Mai, Thailand, 7-9 December 2011.

5. Bernhardt, P.A.; Siefring, C.L. New satellite-based systems for ionospheric tomography and scintillation region imaging. Radio Sci. 2006, 41. [CrossRef]

6. Sze, J.Y.; Hsu, C.-I.G.; Chen, Z.-W.; Chang, C.-C. Broadband CPW-fed circularly polarized square slot antenna with lightening-shaped feed-line and inverted-L grounded strips. IEEE Trans. Antennas Propag. 2010, 58, 973-977. [CrossRef]

7. Chen, Z.-N.; Qing, X. Symmetric-aperture antenna for broadband circular polarization. IEEE Trans. Antennas Propag. 2011, 59, 3932-3936.

8. Row, J.S. The design of a squarer-ring slot antenna for circular polarization. IEEE Trans. Antennas Propag. 2005, 53, 1967-1972. [CrossRef] 
9. Wong, K.L.; Wu, J.Y.; Wu, C.K. A circular-polarized patch loaded square slot antenna. Microw. Opt. Technol. Lett. 1999, 23, 363-365. [CrossRef]

10. Tseng, L.Y.; Han, T.Y. Microstrip-fed circular slot antenna for circular polarization. Microw. Opt. Technol. Lett. 2008, 50, 1056-1058. [CrossRef]

11. Xu, Z.; Liu, J.; Huang, S.; Li, Y. Gain-enhanced SIW cavity-backed slot antenna by using TE $E_{410}$ mode resonance. Int. J. Electron. Commun. 2019, 98, 68-73. [CrossRef]

12. Wong, K.L.; Huang, C.C.; Chen, W.S. Printed ring slot antenna for circular polarization. IEEE Trans. Antennas Propag. 2002, 50, 75-77. [CrossRef]

13. Sze, J.Y.; Chen, W.H. Axial-ratio-bandwidth enhancement of a microstrip-line-fed circularly polarized annular-ring slot antenna. IEEE Trans. Antennas Propag. 2011, 59, 2450-2456. [CrossRef]

14. Qing, X.M.; Chia, Y.W.M. Circularly polarized circular ring slot antenna fed by stripline hybrid coupler. Electron. Lett. 1999, 35, 2154-2155. [CrossRef]

15. Zhang, J.L.; Yang, X.Q. Integrated compact circular polarization annular ring slot antenna design for RFID reader. Prog. Electromagn. Res. Lett. 2013, 39, 133-140. [CrossRef]

16. Chang, T.N.; Lin, J.M. Circularly polarized antenna having two linked slot-rings. IEEE Trans. Antennas Propag. 2011, 59, 3057-3060. [CrossRef]

17. Aziz, M.Z.A.A.; Mufit, N.A.D.A.; Rahim, M.K.A.; Kamaruddin, M.R. Design X-circular polarized with slant rectangular slot by using single port. In Proceedings of the 2012 International Symposium on Antennas and Propagation, Nagoys, Japan, 29 October-2 November 2012; pp. 555-558.

18. Lu, H.J.; Tang, C.L.; Wong, K.L. Single-feed slotted equilateral-triangular microstrip antenna for circular polarization. IEEE Trans. Antennas Propag. 1999, 47, 1174-1178.

19. Ellis, M.S.; Zhao, Z.; Wu, J.; Ding, X.; Nie, Z.; Liu, Q. A novel simple and compact microstrip-fed circularly polarized wide slot antenna with wide axial ratio bandwidth for C-Band applications. IEEE Trans. Antennas Propag. 2016, 64, 1552-1555. [CrossRef]

20. Sung, Y. Bandwidth enhancement of a microstrip line-fed printed wide-slot antenna with a parasitic center patch. IEEE Trans. Antennas Propag. 2012, 60, 1712-1716. [CrossRef]

21. Fu, S.; Kong, Q.; Fang, S.; Wang, Z. Broadband Circularly Polarized Microstrip Antenna with Coplanar Parasitic Ring Slot Patch for L-Band Satellite System Application. IEEE Antennas Wirel. Propag. Lett. 2014, 13, 943-946.

(C) 2019 by the authors. Licensee MDPI, Basel, Switzerland. This article is an open access article distributed under the terms and conditions of the Creative Commons Attribution (CC BY) license (http://creativecommons.org/licenses/by/4.0/). 